Saudi Journal of Medical and Pharmaceutical Sciences

Abbreviated Key Title: Saudi J Med Pharm Sci

ISSN 2413-4929 (Print) |ISSN 2413-4910 (Online)

Scholars Middle East Publishers, Dubai, United Arab Emirates

Journal homepage: https://saudijournals.com/sjmps

Original Research Article

\title{
Evaluation of the Practice of Thromboprophylaxis in Urological Surgery
}

Abdeslam Elkartouti ${ }^{1 *}$, Mohamed Lezrek ${ }^{2}$, Moulay Ahmed Hachimi ${ }^{3}$

${ }^{1}$ Hospital pharmacy service, ${ }^{2}$ Urologycal surgery, ${ }^{3}$ Anesthesia-Intensive Care Service, Hospital Pharmacy Service at Moulay Ismaïl Military Hospital in Meknes and Teacher in the Basic Sciences Department of the Faculty of Medicine and Pharmacy at Sidi Mohammed Ben Abdellah University in Fez Morocco

\author{
DOI: $10.36348 /$ sjmps.2020.v06i06.007 $\quad$ | Received: 05.06.2020 | Accepted: 15.06.2020 | Published: 26.06 .2020 \\ *Corresponding author: EL KARTOUTI Abdeslam
}

\section{Abstract}

The objective of our work is to assess the practice of thromboprophylaxis in urological surgery in relation to international recommendations and to propose corrective measures. This is a prospective observational study of the practice of thromboprophylaxis in urological surgery. Carried out over a period of ten weeks. Data collection was carried out on files developed in consultation; the analysis of the results made it possible to include only the files subject to thromboprophylaxis and the comparison of these results with data from the literature to judge the conformity of the decisions of thromboprophylaxis compared to the specific recommendations. Among the 40 cases collected, one case was excluded because they relate to curative thromboprophylaxis. Compliance with the decision whether or not to initiate thromboprophylaxis concerned only 29 patients out of 39, ie decision compliance of $74.35 \%$. Analysis of the overall thromboembolic risk showed that this risk was high in $35 \%$ of the cases. The duration of thromboprophylaxis was the judgment criterion, the compliance of which was only $63.63 \%$. These results show the interest of this kind of study in order to update our protocols in accordance with the recommendations with regard to thromboprophylactic prevention, it is highly desirable to sensitize health professionals to the importance of respecting the prescription period for better patient management.

Keywords: Urological surgery; prospective study; venous thromboembolic disease; thromboprophylaxis.

Copyright @ 2020: This is an open-access article distributed under the terms of the Creative Commons Attribution license which permits unrestricted use, distribution, and reproduction in any medium for non-commercial use (NonCommercial, or CC-BY-NC) provided the original author and source are credited.

\section{INTRODUCTION}

The prophylaxis of venous thromboembolic disease (VTE) is gaining an increasingly important place in the surgical environment, since numerous studies have well established its efficacy and safety [1]. Numerous clinical guidelines for the use of thromboprophylaxis have been issued. However, thromboprophylaxis remains underused. Hence the interest in carrying out an evaluation study of the practice of thromboprophylaxis in urological surgery in order to assess compliance with international recommendations.

\section{SubJECTS AND MeTHOdS}

This is a prospective observational study of the practice of thromboprophylaxis in urological surgery, carried out at the Moulay Ismail Military Hospital. Data collection was carried out on file developed in consultation and for a period of ten weeks. Analysis of the results made it possible to include only the cards that were the subject of thromboprophylaxis. The analysis of the results made it possible to define the degree of the thromboembolic risk, this degree of the thromboembolic risk took into account the risk linked to the patient and the risk linked to surgery by defining three levels of risk (low $=1$, moderate $=2$, high $=3$ ). This analysis made it possible to study the conformity of the following judgment criteria for each prescription, namely; compliance with the indication for thromboprophylaxis, the appropriate choice of anticoagulant and its route of administration; the adequate schedule for the first administration, compliance with the dosages and the duration of the appropriate treatment. The results were compared to protocols based on the recommendations of the SFAR consensus conference on thromboprophylaxis in surgery. The team developed protocols respecting the recommendations, these protocols were disseminated and displayed in the operating rooms.

\section{RESULTS}

This study was carried out over a ten-week period and made it possible to identify 40 patient files. Of the 40 patients, 32 were male, and 8 were female, with a sex ratio of 4 and an average age of 60 years. 
The age was divided into four groups; the representative groups of our patients were respectively small to large, the age group varying between 0-20 years with $10 \%$; the bracket varying between $41-60$ years with $20 \%$; the age group varying from $61-80$ years with $55 \%$; the age group over 80 with $15 \%$.

The distribution of risk factors in our patients has shown that age over 60 represents $70 \%$, smoking represents $25 \%$, cancer $10.71 \%$, bed rest and diabetes each represent $7.14 \%$.

The interventions that were listed during this study period were mainly: Cholecystitis with $20 \%$ of cases, TRUV with $20 \%$ of cases, followed by prostatectomies with $15 \%$ of cases and NLPC $15 \%$ (Figure 1).

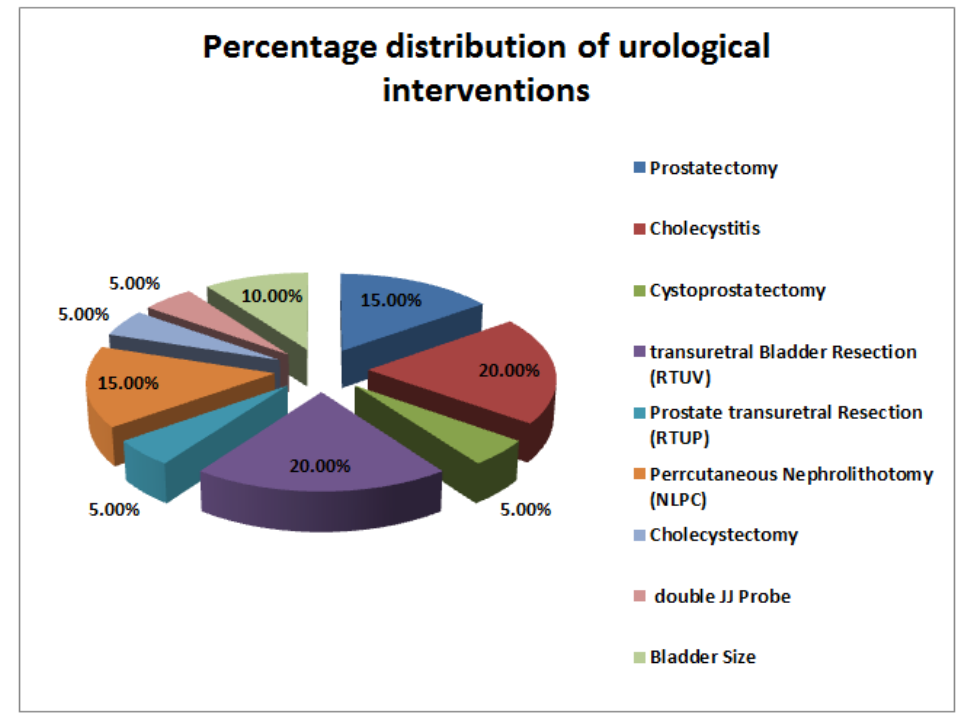

Fig-1: Percentage distribution of urological interventions

Analysis of the degree of thromboembolic risk showed that: (Figure 2)

For the risk analysis related to the patient, the high risk represented $70 \%$, followed by the moderate risk with $15 \%$ and low risk with also $15 \%$.
For the analysis of the risk linked to surgery, the low risk represented $55 \%$, followed by the high risk with $25 \%$, and the low risk with $20 \%$.

Taking into account the two types of risk made it possible to assess the overall thromboembolic risk, so this overall risk was high in $35 \%$ of cases and moderate in $45 \%$ of cases and low in $20 \%$ of cases.

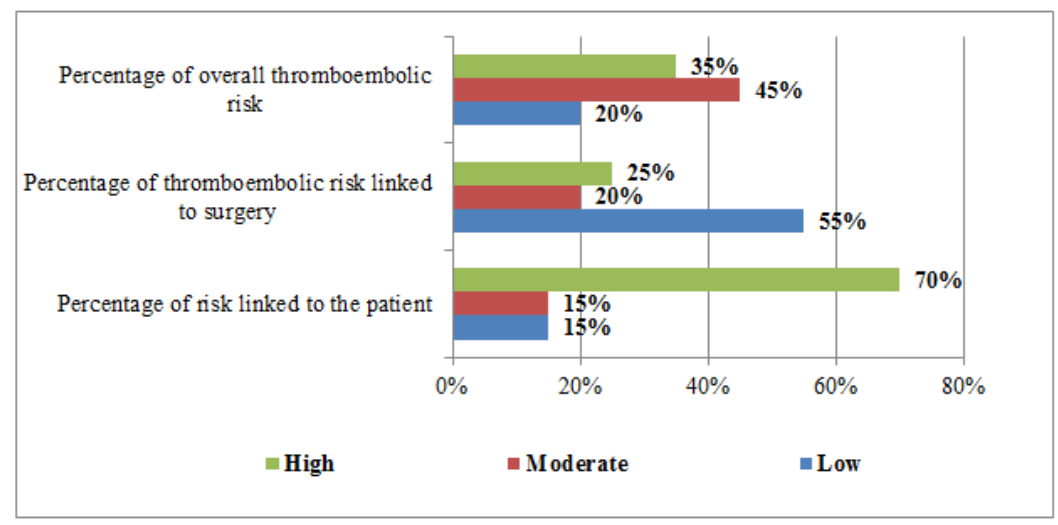

Fig-2: The distribution of the perecentage of degrees of the throboembolic risks

However, the analysis of the judgment criteria for the practice of drug thromboprophylaxis showed that (Figure 3)

$11 / 40$ files were the subject of a theoretical indication for thromboprophylaxis and 18/40 files without a theoretical indication of thromboprophylaxis and one case was excluded because they fall under curative thromboprophylaxis.

) Out of 11 cases presenting the theoretical indication for prevention, thromboprophylaxis was not prescribed by default in 2 cases, 
Out of 18 cases without the theoretical indication for prevention, 8 cases benefited from excess thromboprophylaxis,

Indeed, the conformity of the decision whether or not to initiate thromboprophylaxis concerned only 29 patients out of 39, i.e. decision conformity of $74.35 \%$.

For the compliance of the prescribed molecule, its dosage and the administration schedule, the analysis showed that: Enoxaparin was the molecule chosen and administered for thromboprophylaxis, which constitutes the reference molecule; the conformity of the choice was $100 \%$. The correct schedule for the first administration was compliant in $100 \%$ of the cases; the route of administration was the subcutaneous route and was followed $100 \%$ of the cases. The dosages of the anticoagulant administered were compliant in $100 \%$ of the cases (all the dosages of the anticoagulant were adapted; the weight of the patients was taken into account).

While compliance with the duration of drug thromboprophylaxis presented the major problem and was only adequate at $63.63 \%$.

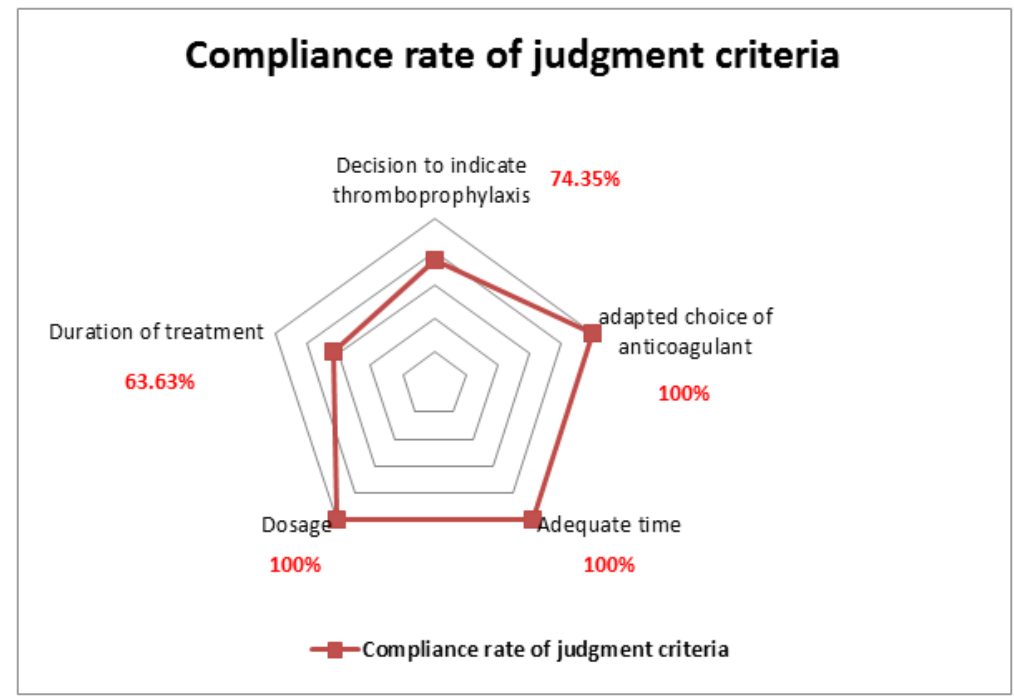

Fig-3: Compliance rate by judgment criteria

\section{DISCUSSIONS}

Venous thromboembolic disease (VTE) is a condition characterized by the formation of a clot inside a vein, whether or not associated with inflammation of the venous wall [2]. MTVE is multifactorial and its risk factors, genetic and environmental, are numerous. These factors must be identified to detect subjects at risk and prevent any thromboembolic event [3]. Venous thromboembolic disease is a frequent complication in the postoperative period with an incidence of $10 \%$ to $50 \%$ in patients without prophylaxis [2]. Hence the need to apply a protocol to prevent this high thromboembolic risk in surgery, in order to reduce the mortality and morbidity associated with pulmonary embolism [4] and secondly, the reduction of deep vein thrombosis (DVT) proximal because of its close association with the incidence of pulmonary embolism and post phlebitic syndrome.

\section{Risks linked to the patient}

A set of personal, congenital or acquired risk factors has been listed by the authors. They undoubtedly increase the thromboembolic risk by adding to the specific risk of the intervention [5-7]. The risk of VTE increases exponentially with age. After 40 years, the risk doubles every 10 years. Beyond 65 , the risk increases more [8. 9]; in our study the rate of patients whose age between 61 and 80 years was $55 \%$ and that of patients whose age over 80 years was $15 \%$. The literature also confirms that tobacco was associated with a moderate increase in the risk of thromboembolism [10]. In our study, the tobacco risk represents $25 \%$. Plaster immobilization, forced bed rest, and lower limb paralysis are associated with an increased risk of venous thromboembolic disease [11, $12]$; in our study, bed rest represents a significant risk factor with a percentage of $7.14 \%$. However, this rate remains lower compared to that recorded by a Canadian study of 2008 where $41.6 \%$ of the patients were bedridden [13]. The presence of cancer roughly increases the risk of venous thromboembolism by eight, it is the third cause of VTE [14], anticancer therapies also favor the appearance of thrombosis, chemotherapy multiplies by 5.6 the risk of thromboembolism venous and the number of thromboembolic events increases with the number of cycles of chemotherapy [15]; in our study, the FDR cancer represents $10.71 \%$. 
Other factors increase the risk of VTE, namely second and third generation contraceptives, respectively increasing the risk of VTE by three to four times [11, 16]. Obesity, defined by a body mass index greater than $30 \mathrm{~kg} / \mathrm{m} 2$, increases the risk of VTE by 1.5 to 3 times [12]. Heart and respiratory failure also contribute to an increased risk of thromboembolism [17]. For the analysis of the risk related to the patient in our study showed that the high risk represented $70 \%$ in our patients.

\section{Risk related to surgery}

Data from the literature show that surgery represents the main risk factor for VTE; it is responsible for around $15 \%$ of all cases of VTE in France [14]. The risk associated with surgery is classified into three levels according to, the SFAR; It ranges from the lowest risk to moderate or high risk [8, 18]. In our study: $20 \%$ of operations are transurethral resections of the bladder; $5 \%$ of transurethral resections of the prostate; $15 \%$ NLPC; $15 \%$ open prostate adenoma surgery; $5 \%$ cystoprostatectomy for bladder tumor. For the analysis of the risk linked to surgery, the high risk represented $25 \%$ in our patients.

\section{The overall thromboembolic risk (table 1)}

The overall thromboembolic risk is the result of the patient risk and the intervention's own risk, this risk is classified into 3 levels: low, moderate, high [8, 18]. The low risk corresponds to minor surgery in patients under 40 , who have no additional risk factor [8]. The moderate risk also corresponds to minor surgery, but in patients who have a personal risk or in patients aged over 40 even if they have no additional risk factor. The high risk corresponds to major surgery (cancer, thrombophilia or undergoing surgery for total prostatectomy or total cystectomy in elderly patients or with an additional risk factor. The overall high risk, in patients concerned by our study, was $35 \%$. Data in the literature report a high thromboembolic risk of $49 \%$ for a French study in 2011 [19] and 57\% for a Canadian study in 2008 [13].

Table-1: Degree of overall risk thromboembolic desease

\begin{tabular}{|c|c|c|c|}
\hline Types of surgeries & Risk linked to surgery & Risk linked to the patient & $\begin{array}{l}\text { Degree of overall risk of } \\
\text { thromboembolic desease }\end{array}$ \\
\hline \multirow{8}{*}{ Urology } & $\begin{array}{l}\text { Surgery testicle penis and } \\
\text { urethra }\end{array}$ & \multirow{8}{*}{ Age $<40$ years/ no risk factor } & \multirow{8}{*}{ Low } \\
\hline & Ureteroscopy & & \\
\hline & RTU prostate & & \\
\hline & RTU bladder & & \\
\hline & Annextomy & & \\
\hline & Tubal Plasty & & \\
\hline & Emergency Cesarean & & \\
\hline & Breast Cancer & & \\
\hline \multirow{7}{*}{ Urology } & Transvesical Adenectomy & \multirow{7}{*}{$\begin{array}{l}\text { Age }>40 \text { years old/, } \\
\text { Estrogen/progetogen, Bed rest } \\
>4 \text { days, Varicose veins, General } \\
\text { or localized Infection, Obesity, } \\
\text { Post-partum }\end{array}$} & \multirow{7}{*}{ Moderate } \\
\hline & Nothing urethra and bladder & & \\
\hline & Retro perotoneal cleaning & & \\
\hline & Urinary Incontinence & & \\
\hline & Kidney Transplant & & \\
\hline & Breast Cancer & & \\
\hline & Uterine Plasty & & \\
\hline \multirow[b]{2}{*}{ Urology } & Total cystectomy & \multirow{2}{*}{$\begin{array}{l}\text { Progressive cancer, } \\
\text { thromboembolic ATCD, MI } \\
\text { Paralysis, Hypercoagubility, } \\
\text { myeloproliferative Syndrome } \\
\text { myéloprolifératif }\end{array}$} & \multirow[b]{2}{*}{ High } \\
\hline & Total Prostatectomy & & \\
\hline
\end{tabular}

\section{Compliance of our preventive practices with the recommendations of thromboprophylaxis}

Analysis of the results of the 39 patients included in our study revealed that the decision to prescribe or not to prescribe thromboprophylaxis according to patient risk and type of surgery was $74.35 \%$ of the total the population studied.
Data from the literature reports that a French study [20] included 89 patients, of which $47.2 \%$ of them presented a theoretical indication for thromboprophylactic treatment, prevention had been established in $95.2 \%$ of these patients, while $21.2 \%$ of those who had no theoretical indication for thrombotic prevention had received excess thromboprophylaxis. 
A Canadian study in 2008 [13] collected 320 patients hospitalized in medical and surgical circles, $57 \%$ of these patients had a theoretical indication for thromboprophylaxis, the percentage of patients who had benefited from prevention had reached $83.7 \%$, whereas less than $5 \%$ of those with no thromboembolic risk had received preventive treatment in excess.

LMWHs constitute the reference drug prevention, this molecule has been prescribed in all our patients. Thus, the compliance of the choice was $100 \%$. It should be noted that the compliance of the subcutaneous route for administration was also $100 \%$. The dosages administered were adapted to the weight of each for each patient, compliance was also $100 \%$. Thromboprophylaxis has been administered in most studies until patients are discharged from the hospital (seven to ten days) [21]. We can estimate that the risk exists until the resumption of a normal ambulation. The recommended duration is seven to ten days except in the case of an oncological intervention where the duration can be extended over four to six weeks [21, 22]. In our study, $63.63 \%$ of patients received thromboprophylaxis for 7-10 days. The duration of thromboprophylactic treatment is the most important criterion for optimal management of the thromboembolic risk in a patient. Respect for the duration of thromboprophylactic treatment is well framed by international standards $[18,23]$ including the recommendations of the SFAR 2011. Thus, insufficient treatment exposes the patient to thromboembolic risks. In order to correct the dysfunctions and bring improvements to the prescription of surgical thromboprophylaxis, it was necessary that the written protocols be revised and disseminated for all surgical procedures. With information and awareness of medical and paramedical executives.

\section{Conclusion}

Today, prophylaxis of VTE in hospitals is a challenge for all practitioners interested in this disease. Prophylaxis for thromboembolic disease was only $74.35 \%$ compliant, this underscores the urgency of disseminating information on the value of thromboprophylaxis and the need to monitor the application of protocols for thromboprophylaxis.

\section{REFERENCES}

1. SAMAMA, M. M., GEROTZIAFAS, G. T., \& HORELlOU, M. H. (2003). Prophylaxie de la maladie veineuse thrombo-embolique: Maladie veineuse thrombo-embolique. La Revue $d u$ praticien (Paris), 53(1), 51-57.

2. Jean-Pierre, W. (2006). Larousse médical. Paris : Hachette livre, 1216.

3. Emile. C. (2012). Facteurs de risque et scores de la maladie thromboembolique veineuse. Option Bio; $467: 17-18$
4. Déry, V., Pharm, B., Rouleau, G., Santerre, D., Paquin, M., Guilbault, D., ... \& Bérubé, M. (2012). L'équipe de projet. Une.

5. Samama1, C.M., Geerts, W.H. (2009). (8th edition) Prevention of intraoperative venous thromboembolism: what is the American College of Chest Physicians Evidence-Based? Clinical Practice Guidelines ; Elsevier Masson SAS. Tous droits réservés).

6. Mouga, N. (2007). Prévention de la maladie thromboembolique veineuse en chirurgie et réanimation.

7. Felber, M., Rozet, F., Droupy, S., Misraï, V., Smadja, D. M., \& Rouprêt, M. (2019). Maladie thromboembolique veineuse et cancers urologiques: épidémiologie et prise en charge thérapeutique. Progrès en urologie, 29(1), 1-11.

8. Samama, C. M., Albaladejo, P., Laversin, S., \& Marret, E. (2005, August). Prévention de la maladie thromboembolique veineuse périopératoire et obstétricale. In Annales francaises d'anesthesie et de reanimation (Vol. 24, No. 8, pp. 853-861). Elsevier Masson.

9. Enga, K. F., Braekkan, S. K., Hansen- Krone, I. J., Le Cessie, S., Rosendaal, F. R., \& HANSEN, J. B. (2012). Cigarette smoking and the risk of venous thromboembolism: the Troms $\varnothing$ Study. Journal of Thrombosis and Haemostasis, 10(10), 2068-2074.

10. Horlander, K. T., Mannino, D. M., \& Leeper, K. V. (2003). Pulmonary embolism mortality in the United States, 1979-1998: an analysis using multiple-cause mortality data. Archives of internal medicine, 163(14), 1711-1717.

11. Ginsberg, J. S., \& Hirsh, J. (2000). Traitement antithrombotique pendant la grossesse. In Annales de cardiologie et d'angéiologie (Paris) (Vol. 49, No. 2, pp. 81-83).

12. Laurent, P., Cellarier, G., Cuguliere, A., Bonal, J., $\&$ Bouchiat, C. (2000). Maladie veineuse thromboembolique au cours de la grossesse. La Presse médicale (1983), 29(1), 39-45.

13. Lanthier, L., Béchard, D., Viens, D., \& Touchette, M. (2011). Évaluation de l'utilisation de la thromboprophylaxie chez les patients hospitalisés dans un centre hospitalier universitaire: un modèle applicable d'évaluation de la qualité de l'acte. Une revue de 320 patients hospitalisés. Journal des Maladies Vasculaires, 36(1), 3-8.

14. Delluc, A., Le Ven, F., Mottier, D., \& Le Gal, G. (2012). Épidémiologie et facteurs de risque de la maladie veineuse thromboembolique. Revue des maladies respiratoires, 29(2), 254-266.

15. Khorana, A. A., Francis, C. W., Culakova, E., Kuderer, N. M., \& Lyman, G. H. (2007). Thromboembolism is a leading cause of death in cancer patients receiving outpatient chemotherapy. Journal of Thrombosis and Haemostasis, 5(3), 632-634. 
16. Léger, P., Barcat, D., Boccalon, C., Guilloux, J., \& Boccalon, H. (2004). Thromboses veineuses des membres inférieurs et de la veine cave inférieure. EMC-Cardiologie-Angéiologie, 1(1), 80-96.

17. Donaldson, G. A., Williams, C., Scannell, J. G., \& Shaw, R. S. (1963). A reappraisal of the application of the Trendelenburg operation to massive fatal embolism: Report of a successful pulmonary-artery thrombectomy using a cardiopulmonary bypass. New England journal of medicine, 268(4), 171-174.

18. Samama, C. M., Gafsou, B., Jeandel, T., Laporte, S., Steib, A., Marret, E., ... \& Rosencher, N. (2011). Prévention de la maladie thromboembolique veineuse postopératoire. Actualisation 2011. Texte court French Society of Anaesthesia and Intensive Care. Guidelines on perioperative venous thromboembolism prophylaxis. Update 2011. Short text. In Annales Françaises d'Anesthésie et de Réanimation (Vol. 30, pp. 947-951).

19. Bergmann, J. F., Lloret-Linares, C., Rami, A., Cohen, A. T., Garay, R. P., Kakkar, A. K., ... \& Anderson, F. A. (2011). Risque thromboembolique veineux et pratique de prévention hospitalière: résultats obtenus en France de l'étude internationale ENDORSE. $\mathrm{La}$ Presse Médicale, 40(12), e528-e537.

20. Magy-Bertrand, N., Auzas, O., Meaux-Ruault, N., Hafsaoui, C., \& Gil, H. (2010). Évaluation de la thromboprophylaxie dans un service de médecine interne. La Revue de médecine interne, 31(6), 406410.

21. Société Française d'Anesthésie et de Réanimation. (2005, August). Prévention de la maladie thromboembolique veineuse périopératoire et obstétricale: Recommandations pour la pratique clinique. Texte court 2005. In Annales francaises d'anesthesie et de reanimation (Vol. 24, No. 8, pp. 952-976). Elsevier Masson.

22. Geerts, W. H., Bergqvist, D., Pineo, G. F., Heit, J. A., Samama, C. M., Lassen, M. R., \& Colwell, C. W. (2008). Prevention of venous thromboembolism: American College of Chest Physicians evidence-based clinical practice guidelines. Chest, 133(6), 381S-453S.

23. Violette, P. D., Lavallée, L. T., Kassouf, W., Gross, P. L., \& Shayegan, B. (2019). Guide de pratique de l'Association des urologues du Canada: thromboprophylaxie peropératoire et traitement anticoagulant. CUAJ, 13(4), R12. 